\title{
Short-term forecasting of salinity intrusion in Ham Luong river, Ben Tre province using Simple Exponential Smoothing method
}

\author{
Dự báo ngắn hạn xâm nhập mặn trên sông Hàm Luông, tỉnh Bến Tre bằng phương pháp \\ Simple Exponential Smoothing
}

\begin{abstract}
TRAN, Thai Thanh*; NGO, Quang Xuan¹,2; HA, Hieu Hoang ${ }^{3}$; NGUYEN, Nhan Phan ${ }^{4}$
'Institute of Tropical Biology, Vietnam Academy of Science and Technology, 85 Tran Quoc Toan Street, District 3, Ho Chi Minh City, Vietnam; ${ }^{2}$ Graduate University of Science and Technology, Vietnam Academy of Science and Technology, 18 Hoang Quoc Viet Street, Cau Giay District, Hanoi City, Vietnam; ${ }^{3}$ Binh Duong University, 504 Binh Duong Highway, Binh Duong Province, Vietnam; ${ }^{4}$ Center of Natural Resources and Environment Monitoring, Ben Tre Province's Department of Natural Resources and Environment, 38 Cach Mang Thang Tam Street, Ward 3, Ben Tre Province, Vietnam
\end{abstract}

\begin{abstract}
Salinity intrusion in a river may have an adverse effect on the quality of life and can be perceived as a modern-day curse. Therefore, it is important to find technical ways to monitor and forecast salinity intrusion. In this paper, we designed a forecasting model using Simple Exponential Smoothing method (SES) which performs weekly salinity intrusion forecast in Ham Luong river (HLR), Ben Tre province based on historical data obtained from the Center for Hydro-meteorological forecasting of Ben Tre province. The results showed that the SES method provides an adequate predictive model for forecast of salinity intrusion in An Thuan, Son Doc, and Phu Khanh. However, the SES in My Hoa, An Hiep, and Vam Mon could be improved upon by another forecasting technique. This study suggests that the SES model is an easy-to-use modeling tool for water resource managers to obtain a quick preliminary assessment of salinity intrusion.
\end{abstract}

\begin{abstract}
Xâm nhập mặn có thể gây tác động xấu đến đời sống con người, tuy nhiên nó hoàn toàn có thể dự báo được. Cho nên, một điều quan trọng là tìm được phương pháp kỹ thuật phù hợp để dự báo và giám sát xâm nhập mặn trên sông. Trong bài báo này, chúng tôi sử dụng phương pháp Simple Exponential Smoothing để dự báo xâm nhập mặn trên sông Hàm Luông, tỉnh Bến Tre. Kết quả cho thấy mô hình dự báo phù hợp cho các vị trí An Thuận, Sơn Đốc, và Phú Khánh. Tuy nhiên, các vị trí Mỹ Hóa, An Hiệp, và Vàm Mơn có thể tìm các phương pháp khác phù hợp hơn. Phương pháp Simple Exponential Smoothing rất dễ ứng dụng trong quản lý nguồn nước dựa vào việc cảnh báo xâm nhập mặn.
\end{abstract}

Keywords: Ben Tre province, Ham Luong river, salinity intrusion, Simple Exponential Smoothing

\section{Introduction}

In Phnom-Penh (Cambodia), Mekong river divides into two branches: the Hau river (known as the Bassac river) and the Tien river (also known as the Mekong river) that enter Vietnam separately. Regarding Tien river, it divides into two sub-branches: the My Tho and Co Chien river. The My Tho river splits into four smaller branches: the Tieu, Dai, Ba Lai and Ham Luong, of which the Ba Lai branch is closed off by dam construction. The Co Chien separates into two smaller branches: The Co Chien and Cung Hau. Ben Tre province is one of the 13 provinces that make up the Mekong Delta. Hydro-conditions in Ben Tre Province has been affected mainly by three rivers: Dai, Ham Luong, and Co Chien (Tran and Nguyen, 2006). The Ham Luong river (HLR) flows completely within Ben Tre province and it is responsible for the supply of fresh-water, sediments, and nutrients to this province. Furthermore, the river's water availability plays a crucial role in local economic development due to the large quantity of transport via ships and supports the agricultural sector (Thach and Doan, 2001).

Salinity intrusion is a natural phenomenon and frequently occurred in HLR (particular in the dry season) (Hang et al., 2015). Several factors affected the salinity intrusion in HLR as follows: sea level rise and reduction of rainfall during the dry season. Furthermore, hydropower dams in upstream countries could enhance this problem (Nguyen et al., 2008). Increasing salinity intrusion in HLR not only damages hugely productive rice fields, fruit, vegetable gardens but also causes tremendous difficulties for freshwater-based aquaculture development (Phuong et 
al., 2018). Accurate information for salinity prediction will become more difficult due to climate change and extreme weather. Therefore, salinity intrusion has been of particular interest in the Mekong river systems generally and in HLR in particular; it is necessary to have a research about forecasting of salinity intrusion for providing salinity information to different target groups. from managers to local people.

Various methods have been developed to assist in the forecast of salinity intrusion in rivers. Hydrodynamic models, like the 3-D Curvilinear-grid Hydrodynamic (CH3D) circulation model (Sheng, 1990), the Environmental Fluid Dynamics Code (EFDC) (Hamrick, 1992), and an artificial neural network (ANN) (Huang and Foo, 2002). Remote sensing techniques have been used successfully for detecting salinity intrusion and demonstrated in different studies using satellite-based information (Phuong et al., 2018). However, these models require detailed assessment of irregular coastal geometry, complicated bottom bathymetry, tides, and wind effects (Qiu and Wan, 2013). Over the past decade, there has been growing interest in using Exponential Smoothing Method, an intuitive forecasting method that weights the observed time series unequally. Recent observations are weighted more heavily than remote observations. The unequal weighting is accomplished by using one or more smoothing parameters, which determine how much weight is given to each observation (Zhi-Peng et al., 2008). The simplest of the exponentially smoothing methods are naturally called Simple Exponential Smoothing (SES). SES is appropriate for a series that moves randomly above and below a constant mean (stationary series). This method is suitable for forecasting data with no clear trend or seasonal pattern (Yorucu, 2003). Exponential smoothing method, particularly SES, is a widely used method in time series analysis due to its simplicity, its computational efficiency, the easiness of adjusting its responsiveness to changes in the process being forecasted, and its reasonable accuracy (Montgomery, 1990). SESs have been used in different prediction research, such as fine particulate matter (PM2.5) concentrations monitoring and forecasting (Mahajan et al., 2018), as well as in short-term travel time forecasting of the urban arterial street (ZhiPeng el al., 2008). However, models to predict salinity intrusion in river are lacking.

The aim of the present study was to develop the SES to forecast the salinity intrusion in HLR, Ben Tre province by using salinity monitoring data from January 2017 to March 2019.

\section{Materials and methods}

\subsection{Study area}

HLR (in Vietnamese: Sông Hàm Luông) is a branch of Mekong river in the Mekong Delta region, Vietnam. The river is located within a quadrat bounded by $9^{0} 56^{\prime}-10^{0} 16^{\prime} \mathrm{N}$, 106008'-106037'E (Figure 1). Its mean length, width, and depth are 70 km, 1,200-1,500 m, and 12-16 m (Nguyen et al., 2008). The river plays a pivotal role in supplying freshwater for agriculture, industry, domestic applications, and other economic activities such as navigation, tourism, aquaculture (Thach and Doan, 2001).

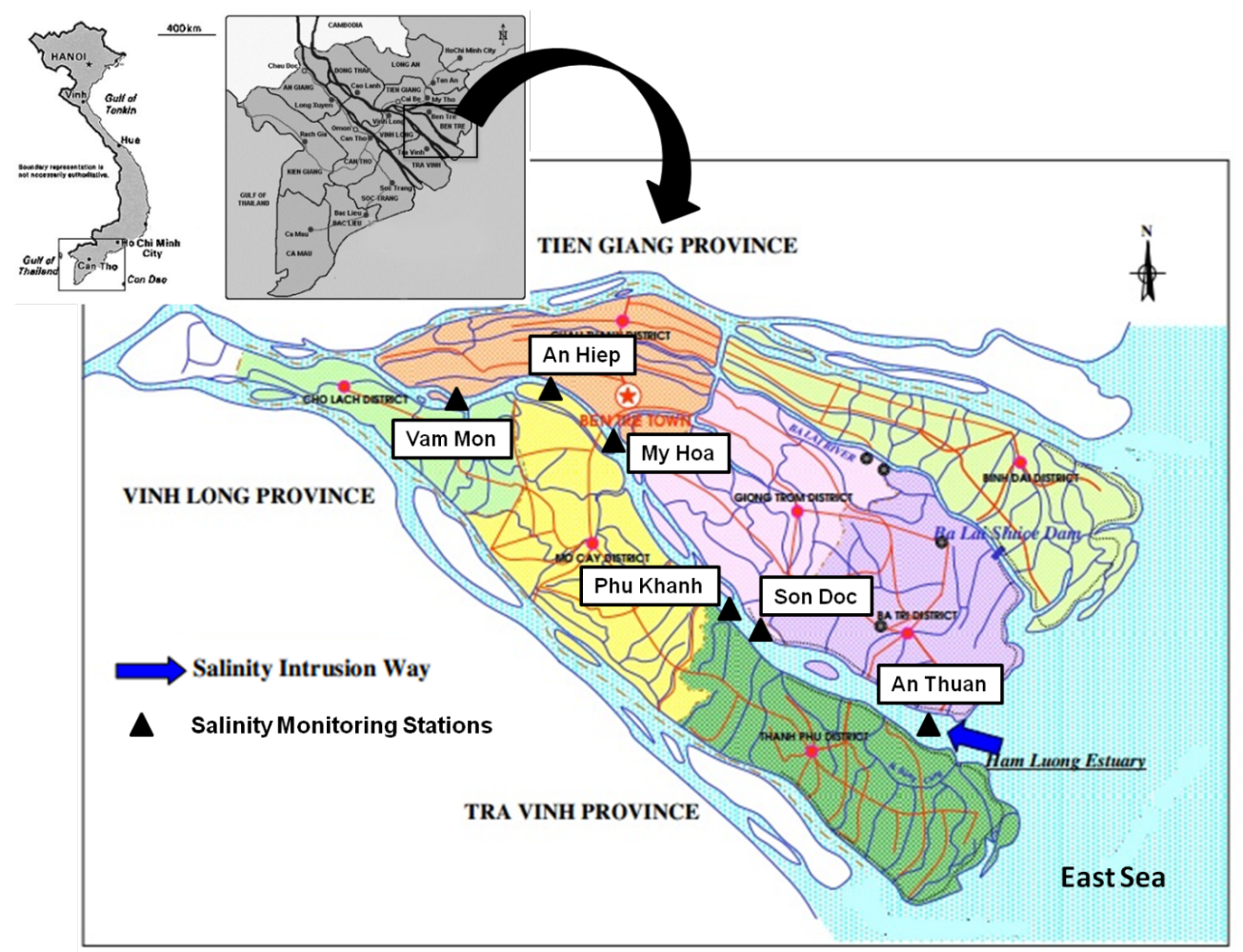

Figure 1. Map of the Ham Luong River, Ben Tre province showing the location of present study stations (An Thuan, Son Doc, Phu Khanh, My Hoa, An Hiep, and Vam Mon) for Simple Exponential Smoothing method 


\subsection{Description of the Ham Luong river's salinity monitoring data set}

In HLR, there are six salinity monitoring stations (from estuary to upstream) located at An Thuan (Tiem Tom harbour, Ba Tri district), Son Doc (Hung Le commune, Giong Trom district), Phu Khanh (Phu Khanh commune, Thanh Phu district), My Hoa (Ben Tre city), An Hiep (An Hiep commune, Chau Thanh district), and Vam Mon (Phu Son commune, Cho Lach district) (Figure 1). In each station, the salinity monitoring data were collected one time per week for a period of 23 weeks (from January to June that is dry season in Mekong Delta). The river salinity monitoring data during 2017, 2018, and 2019 were provided by the Center for Hydro-meteorological forecasting of Ben Tre province (available at http://www.bentre.gov.vn/Lists/ ThongTinCanBiet/TongQuat.aspx). Except for salinity data in 2019, the values were collected for 11 weeks (from Jan 1st-Jan 8th to Mar 12th-Mar 19th). This paper presents a prediction of salinity intrusion in HLR from Mar $19^{\text {th }}-$ Mar $26^{\text {th }}$ (week 58) to Jun $4^{\text {th }}$-Jun $11^{\text {st }}$ (week 69) of 2019, based on salinity monitoring data from January 2017 to March 2019.

\subsection{Simple Exponential Smoothing}

Using the SES method, all forecasts for the future are equal to the last observed value of the series. $Y_{t+1}$ is the forecast value of the variable $Y$ at the time $t\left(Y_{t}\right)$, the SES equation takes the form of:

$Y_{t+1}=Y_{t}$

Using the average method, all future forecasts are equal to a simple average of the observed data.

$\mathrm{Y}_{\mathrm{t}+1}=\frac{1}{T} \sum_{t=1}^{T} Y t$

Forecasts are calculated using weighted averages, where the weights decrease exponentially as observations come from further in the past - the smallest weights are associated with the oldest observations:

$Y_{t+1}=a Y_{t}+a(1-a) Y_{t-1}+a(1-a)^{2} Y_{t-2}+\ldots$

where $0 \leq \mathrm{a} \leq 1$ is the smoothing parameter. The one-stepahead forecast for time $T+1$ is a weighted average of all of the observations in the series $\mathrm{y}_{1}, \ldots, \mathrm{y}_{\mathrm{T}}$. The rate at which the weights decrease is controlled by the parameter a.

For any a between 0 and 1, the weights attached to the observations decrease exponentially as we go back in time, hence the name "exponential smoothing". If a is small (i.e., close to 0 ), more weight is given to observations from the more distant past. If a is large (i.e., close to 1), more weight is given to the more recent observations. For the extreme case where $\alpha=1, Y_{t+1}=Y_{t}$, and the forecasts are equal to the last observed value. The SES formulation has been described in detail by Ostertagova and Ostertag (2012).

\subsection{Method application}

To make forecasts using SES in RStudio (Ver 1.1.453, R Core Team, 2016), we can fit the SES predictive model using the "HoltWinters()" function in R (with set the parameters beta=FALSE and gamma=FALSE in the HoltWinters() function). Also, we can make forecasts for further time points by using the "forecast.HoltWinters()" function in the R "forecast" package.

\section{Results and discussion}

\subsection{Salinity intrusion in Ham Luong river from January 2017 to March 2019}

In 2017, the salinity concentration (\%o) in An Thuan and Son Doc station were considerably higher than the remaining stations (Phu Khanh, My Hoa, An Hiep, and Vam Mon). More specifically, An Thuan station was expressed as the highest salinity concentration (from 15.00 to 29.00) followed by Son Doc station (0.40-13.10) and Phu Khanh (0.40-9.10). By contrast, My Hoa, An Hiep, and Vam Mon stations recorded low salinity concentration, ranged from 0.10 to 2.60, $0.10-1.00$, and $0.10-0.20$, respectively. In 2017, salinity in week 10 (Mar $7^{\text {th }}$-Mar $14^{\text {th }}$ ) was highest, however, the lowest salinity was observed in week 23 (Jun $6^{\text {th }}$-Jun $\left.13^{\text {rd }}\right)$. Salinity intrusion trend in Ham Luong river was: the maximum salinity concentration occurred in March, April, and some weeks of the beginning of May. In the end of dry season (June), the salinity concentration decreased rapidly (Figure 2).

In 2018, the salinity concentration in six salinity monitoring stations in HLR was considerably lower than those in 2017. Salinity in week 37 (Apr $3^{\text {rd }}-$ Apr 10 ${ }^{\text {th }}$ ) was highest: An Thuan station (26.40\%0), Son Doc (14.80\%0), My Hoa (3.5\%), An Hiep (1.5\%0), and Vam Mon (0.2\%0), except for Phu Khanh station (highest salinity in week 40, 8.80\%0). In turn, the lowest salinity was expressed in week 45 (May $29^{\text {th }}$-Jun $5^{\text {th }}$ ). As the same to results of salinity intrusion trend in 2017, the maximum salinity concentration recorded in March, April, and some weeks of the beginning of May. Furthermore, the salinity concentration decreased rapidly in June. However, the maintaining time of high salinity was longer than those in 2017 (Figure 2).

From January to March 2019, although it was the beginning of dry season, the salinity in six salinity monitoring stations in HLR was recorded with high concentration. More specifically, in week 48 (Jan $8^{\text {th }}$-Jan $\left.15^{\text {th }}\right)$, the salinity concentration in An Thuan station reaches 25.80\%o followed by Son Doc station (10.30\%) and Phu Khanh (9.90\%) (Figure 2). Perhaps salinity concentration during the driest months of 2019 (from March to May) in HLR, is continuing to climb.

As a result of Cowardin et al. (1979), water was classified into five categories based on salinity concentration, 
ranging from fresh (0 to $0.5 \%$ ) to hyperhaline (>40\%). They further subdivided the brackish habitat types ( 0.5 to $30 \%$ ) into: oligohaline (0.5 to 5\%), mesohaline (5 to 18\%), and polyhaline (18 to 30\%). Therefore, water in An Thuan station (estuary) was assigned to polyhaline conditions, whereas water in Vam Mon station (upstream) could be classified as freshwater conditions. However, in the dry season 2018, salinity intruded seriously with high concentration and further to inland than those in 2017. Water in An Hiep station was assigned to freshwater during monitoring time in 2017 but it was assigned to oligohaline from week 34-40 of 2018. Furthermore, the maintaining time of oligohaline conditions in My Hoa station in 2018 was longer than those in 2017 (Figure 2).

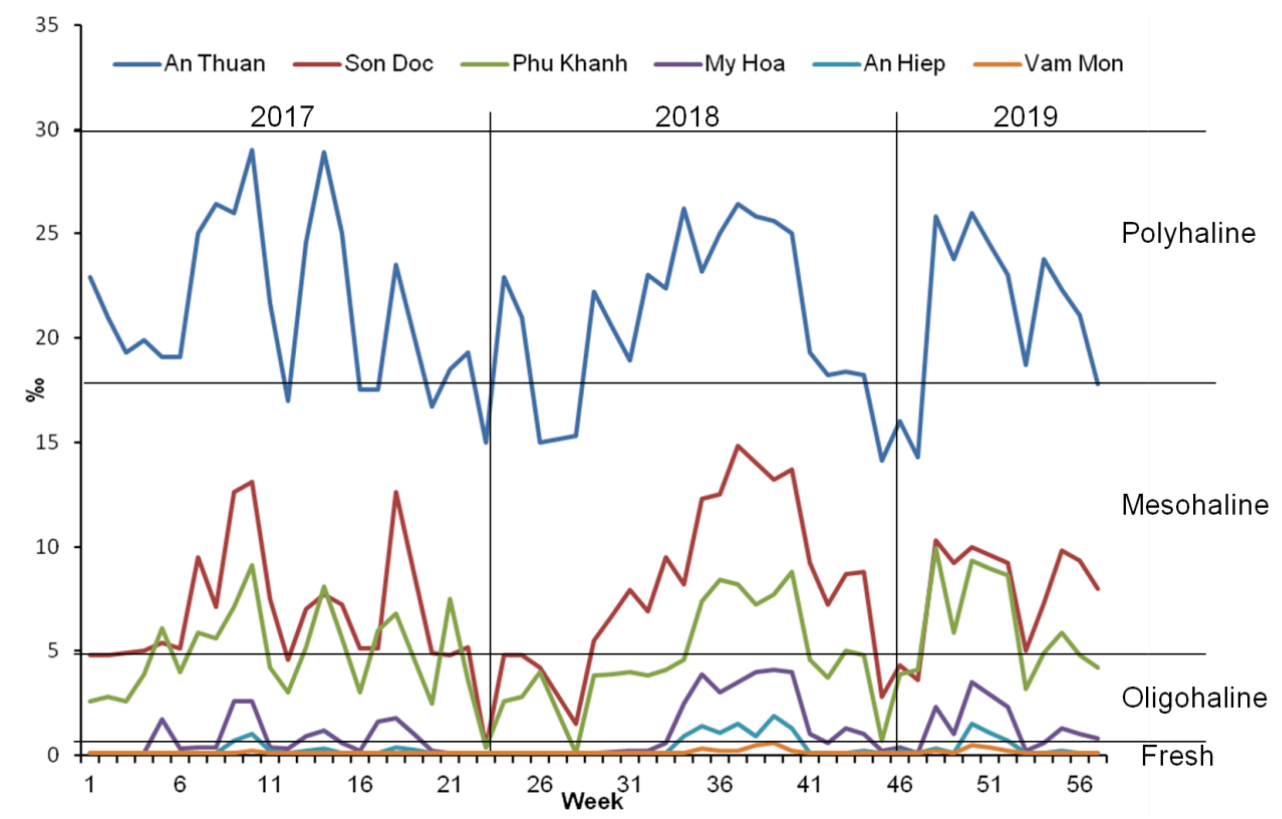

Figure 2. Salinity monitoring data in Ham Luong River, Ben Tre Province from January 2017 to March 2019

\subsection{Short-term forecasting of salinity intrusion in Ham Luong river by Simple Exponential Smoothing}

At each station, the SES method gives the forecast for 12 weeks, an $80 \%$ prediction interval for the forecast, and a 95\% prediction interval for the forecast. For example, the forecasted salinity concentration for week 58 in An Thuan station is about $19.32 \%$, with a $95 \%$ prediction interval of (11.98\%o/26.65\%), Son Doc (8.35\%o, 3.01\%o/13.71\%o), Phu Khanh (4.75\%o, 0.38\%o/9.12\%o), My Hoa (0.84\%o, 0.00\%o/2.78\%o), An Hiep (0.10\%, 0.00\%o/2.78\%o), and Vam Mon $(0.10 \%$, $0.00 \% / 0.30 \%$ ). The forecasts for salinity concentration in six salinity monitoring stations in HLR from week 59 to week 69 was given in Table 1.

Table 1. Short-term forecasting of salinity intrusion (\%o) in Ham Luong River for the weeks 58-69 (12 more weeks). For: Point Forecast, $80 \%$ (L/H): the $80 \%$ prediction interval (low/high), 95\% (L/H): the 95\% prediction interval (low/high)

\begin{tabular}{lllllll}
\multirow{2}{*}{ Week } & An Thuan & \multicolumn{5}{c}{ Son Doc } \\
\cline { 2 - 7 } & For & $80 \%(\mathrm{~L} / \mathrm{H})$ & $95 \%(\mathrm{~L} / \mathrm{H})$ & For & $80 \%(\mathrm{~L} / \mathrm{H})$ & $95 \%(\mathrm{~L} / \mathrm{H})$ \\
\hline $\mathbf{5 8}$ & 19.32 & $14.52 / 24.12$ & $11.98 / 26.65$ & 8.35 & $4.86 / 11.86$ & $3.01 / 13.71$ \\
$\mathbf{5 9}$ & 19.32 & $13.72 / 24.92$ & $10.76 / 27.88$ & 8.35 & $4.09 / 12.63$ & $1.83 / 14.89$ \\
$\mathbf{6 0}$ & 19.32 & $13.02 / 25.62$ & $9.69 / 28.95$ & 8.35 & $3.44 / 13.28$ & $0.83 / 15.89$ \\
$\mathbf{6 1}$ & 19.32 & $12.4 / 26.25$ & $8.73 / 29.91$ & 8.35 & $2.86 / 13.86$ & $-0.05 / 16.77$ \\
$\mathbf{6 2}$ & 19.32 & $11.82 / 26.82$ & $7.85 / 30.79$ & 8.35 & $2.34 / 14.38$ & $-0.84 / 17.56$ \\
$\mathbf{6 3}$ & 19.32 & $11.29 / 27.36$ & $7.04 / 31.61$ & 8.35 & $1.86 / 14.86$ & $-1.58 / 18.29$ \\
$\mathbf{6 4}$ & 19.32 & $10.79 / 27.86$ & $6.27 / 32.38$ & 8.35 & $1.42 / 15.30$ & $-2.26 / 18.98$ \\
$\mathbf{6 5}$ & 19.32 & $10.32 / 28.34$ & $5.55 / 33.10$ & 8.35 & $1.00 / 15.72$ & $-2.90 / 19.62$ \\
$\mathbf{6 6}$ & 19.32 & $9.87 / 28.79$ & $4.86 / 33.79$ & 8.35 & $0.60 / 16.12$ & $-3.50 / 20.22$ \\
$\mathbf{6 7}$ & 19.32 & $9.44 / 29.21$ & $4.20 / 34.45$ & 8.35 & $0.23 / 16.49$ & $-4.08 / 20.80$ \\
$\mathbf{6 8}$ & 19.32 & $9.03 / 29.63$ & $3.57 / 35.08$ & 8.35 & $-0.14 / 16.85$ & $-4.63 / 21.35$ \\
$\mathbf{6 9}$ & 19.32 & $8.63 / 30.02$ & $2.97 / 35.68$ & 8.35 & $-0.48 / 17.20$ & $-5.16 / 21.88$ \\
\hline \multirow{2}{*}{ Week } & Phu Khanh & & & My Hoa & & \\
\hline $\mathbf{5 8}$ & For & $80 \%(\mathrm{~L} / \mathrm{H})$ & $95 \%(\mathrm{~L} / \mathrm{H})$ & For & $80 \%(\mathrm{~L} / \mathrm{H})$ & $95 \%(\mathrm{~L} / \mathrm{H})$ \\
\hline
\end{tabular}




\begin{tabular}{|c|c|c|c|c|c|c|}
\hline 59 & 4.75 & $1.58 / 7.91$ & $-0.09 / 9.59$ & 0.84 & $-0.80 / 2.48$ & $-1.67 / 3.35$ \\
\hline 60 & 4.75 & $1.30 / 8.19$ & $-0.52 / 10.02$ & 0.84 & $-1.11 / 2.79$ & $-2.14 / 3.82$ \\
\hline 61 & 4.75 & $1.04 / 8.45$ & $-0.92 / 10.42$ & 0.84 & $-1.37 / 3.05$ & $-2.55 / 4.23$ \\
\hline 62 & 4.75 & $0.80 / 8.70$ & $-1.29 / 10.79$ & 0.84 & $-1.61 / 3.29$ & $-2.91 / 4.59$ \\
\hline 63 & 4.75 & $0.57 / 8.93$ & $-1.64 / 11.14$ & 0.84 & $-1.82 / 3.50$ & $-3.23 / 4.91$ \\
\hline 64 & 4.75 & $0.35 / 9.14$ & $-1.97 / 11.47$ & 0.84 & $-2.02 / 3.70$ & $-3.54 / 5.22$ \\
\hline 65 & 4.75 & $0.15 / 9.35$ & $-2.29 / 11.79$ & 0.84 & $-2.21 / 3.89$ & $-3.82 / 5.50$ \\
\hline 66 & 4.75 & $-0.05 / 9.55$ & $-2.59 / 12.09$ & 0.84 & $-2.38 / 4.06$ & $-4.09 / 5.77$ \\
\hline 67 & 4.75 & $-0.24 / 9.74$ & $-2.88 / 12.38$ & 0.84 & $-2.55 / 4.23$ & $-4.35 / 6.02$ \\
\hline 68 & 4.75 & $-0.43 / 9.92$ & $-3.16 / 12.66$ & 0.84 & $-2.71 / 4.39$ & $-4.59 / 6.27$ \\
\hline 69 & 4.75 & $-0.60 / 10.10$ & $-3.43 / 12.93$ & 0.84 & $-2.86 / 4.54$ & $-4.82 / 6.50$ \\
\hline \multirow{2}{*}{ Week } & \multicolumn{3}{|c|}{ An Hiep } & \multicolumn{3}{|c|}{ Vam Mon } \\
\hline & For & $80 \%(\mathrm{~L} / \mathrm{H})$ & $95 \%(\mathrm{~L} / \mathrm{H})$ & For & $80 \%(\mathrm{~L} / \mathrm{H})$ & $95 \%(L / H)$ \\
\hline 58 & 0.10 & $-0.39 / 0.60$ & $-0.65 / 0.86$ & 0.10 & $-0.03 / 0.23$ & $-0.10 / 0.30$ \\
\hline 59 & 0.10 & $-0.53 / 0.73$ & $-0.86 / 1.07$ & 0.10 & $-0.06 / 0.26$ & $-0.14 / 0.34$ \\
\hline 60 & 0.10 & $-0.64 / 0.85$ & $-1.03 / 1.24$ & 0.10 & $-0.08 / 0.28$ & $-0.18 / 0.38$ \\
\hline 61 & 0.10 & $-0.74 / 0.95$ & $-1.18 / 1.39$ & 0.10 & $-0.10 / 0.30$ & $-0.21 / 0.41$ \\
\hline 62 & 0.10 & $-0.83 / 1.03$ & $-1.32 / 1.53$ & 0.10 & $-0.12 / 0.32$ & $-0.24 / 0.44$ \\
\hline 63 & 0.10 & $-0.91 / 1.11$ & $-1.44 / 1.65$ & 0.10 & $-0.14 / 0.34$ & $-0.27 / 0.47$ \\
\hline 64 & 0.10 & $-0.98 / 1.19$ & $-1.55 / 1.76$ & 0.10 & $-0.16 / 0.36$ & $-0.29 / 0.49$ \\
\hline 65 & 0.10 & $-1.05 / 1.26$ & $-1.66 / 1.87$ & 0.10 & $-0.17 / 0.37$ & $-0.31 / 0.52$ \\
\hline 66 & 0.10 & $-1.12 / 1.32$ & $-1.76 / 1.97$ & 0.10 & $-0.19 / 0.39$ & $-0.34 / 0.54$ \\
\hline 67 & 0.10 & $-1.18 / 1.38$ & $-1.86 / 2.06$ & 0.10 & $-0.20 / 0.40$ & $-0.36 / 0.56$ \\
\hline 68 & 0.10 & $-1.24 / 1.44$ & $-1.95 / 2.15$ & 0.10 & $-0.21 / 0.41$ & $-0.38 / 0.58$ \\
\hline 69 & 0.10 & $-1.29 / 1.50$ & $-2.03 / 2.24$ & 0.10 & $-0.23 / 0.43$ & $-0.40 / 0.60$ \\
\hline
\end{tabular}

Notes: negative value means zero
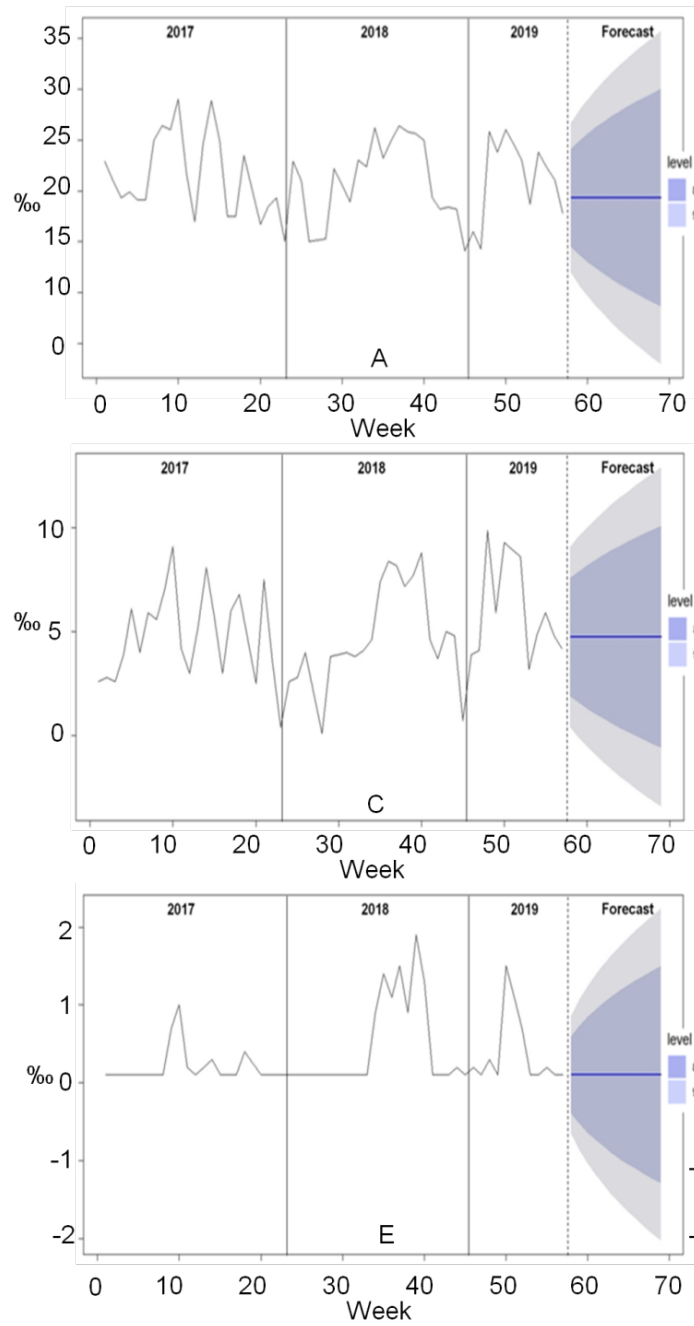
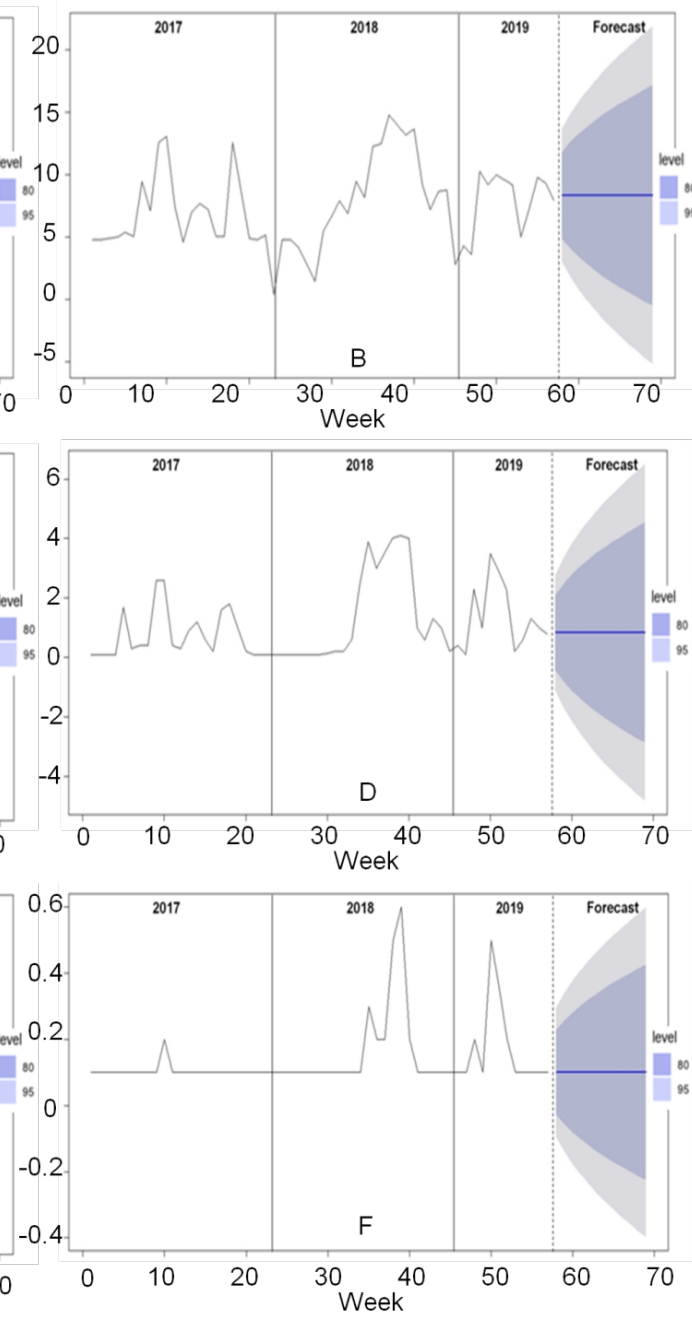

Figure 3. Simple exponential smoothing applied to forecast of salinity intrusion in An Thuan (A), Son Doc (B), Phu Khanh (C), My Hoa (D), An Hiep (E), Vam Mon $(F)$ in Ham Luong river from week 582019 (Mar 19th-Mar 26th) to week 692019 (Jun 4th-Jun 11st).

Note: negative values means zero. 
Figure 3 shows the forecasts for salinity concentration in six salinity monitoring stations in HLR from week 58 to week 69 that is plotted as a blue line, the $80 \%$ prediction interval as a dark shaded area, and the 95\% prediction interval as a lightly shaded area.

\subsection{Testing predictive model}

As mentioned in Hyndman and Athanasopoulos (2018), three measures of the accuracy of the predictive model are: (i) the forecast errors (calculated as the observed values minus predicted values, for each time point) are normally distributed, (ii) the in-sample forecast errors are non-autocorrelations, and (iii) constant variance.

The Ljung-Box test statistic for in-sample forecast errors for An Thuan model was 17.4, and p-value was 0.12 (>0.05), so there was little evidence of autocorrelations in the in- sample forecast errors at lags 1-20. The similar result was found in the remaining model (Table 2).

Table 2. Results of the Ljung-Box test for in-sample forecast errors for six stations in Ham Luong River

Predictive model Ljung-Box test statistic

\begin{tabular}{lll}
\hline An Thuan & 27.61 & 0.12 \\
Son Doc & 20.08 & 0.45 \\
Phu Khanh & 28.03 & 0.10 \\
My Hoa & 24.68 & 0.21 \\
An Hiep & 19.35 & 0.50 \\
Vàm Mon & 24.14 & 0.36 \\
\hline
\end{tabular}

To check whether the forecast errors have constant variance, we can make a time plot of the in-sample forecast errors. A time plot of the in-sample forecast errors of An Thuan, Son Doc, and My Hoa seem to have constant variance over time, whereas others did not (Figure 4).
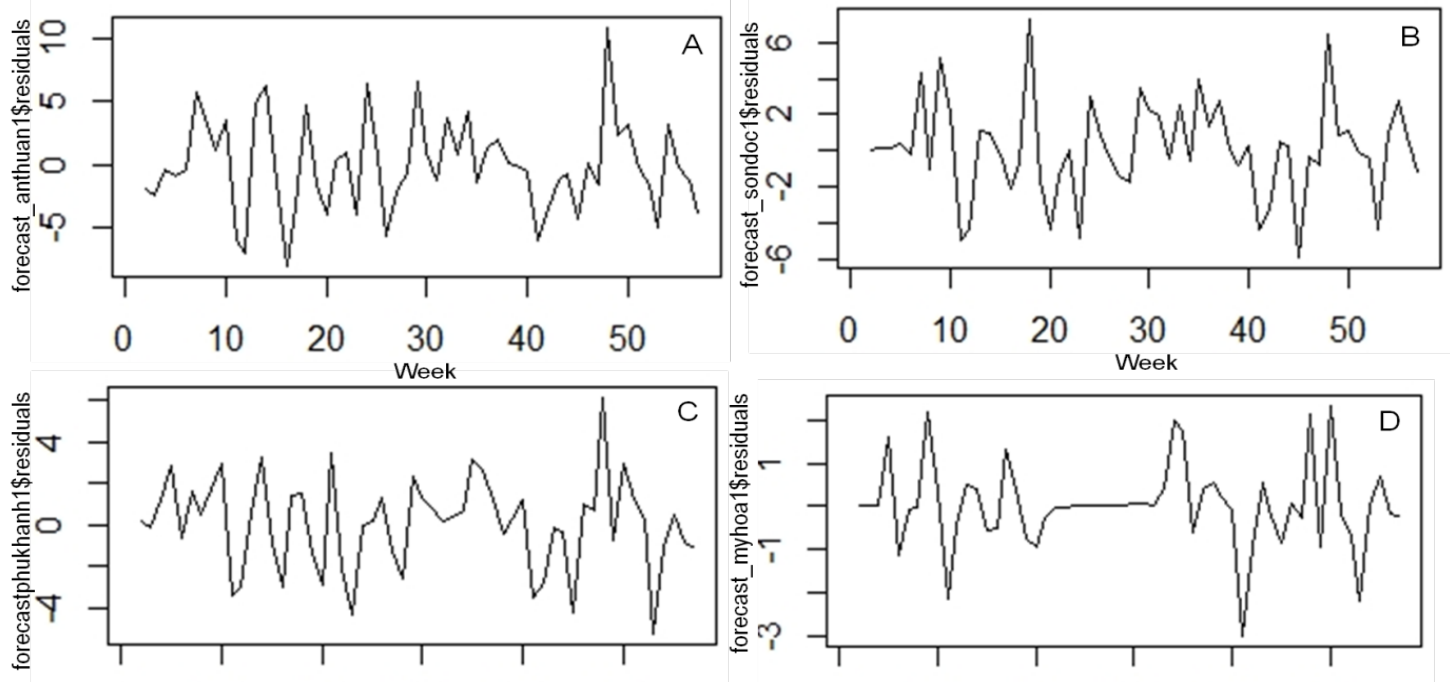

$\begin{array}{lllll}0 & 10 & 20 & 30 & 30 \\ \text { Week }\end{array}$
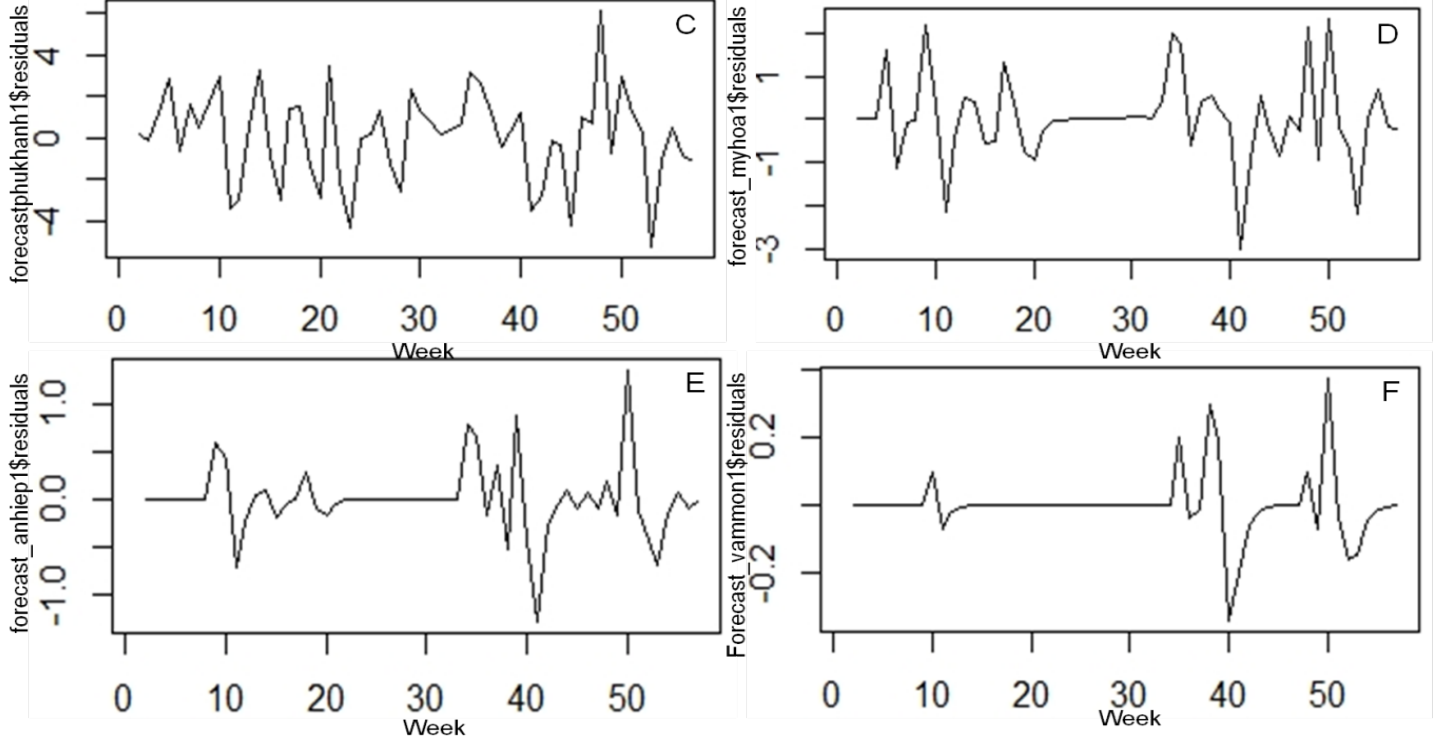

Figure 4. A time plot of the in-sample forecast errors of six predictive model in An Thuan (A), Son Doc (B), Phu Khanh (C), My Hoa (D), An Hiep (E), Vam Mon (F) in Ham Luong river

In order to check whether the forecast errors of six predictive models in HLR are normally distributed with mean zero, we can plot a histogram of the forecast errors, with an overlaid normal curve that has mean zero and the same standard deviation as the distribution of forecast errors. Figure 5 shows that the distribution of forecast errors of six predictive model seems to be normally distributed with mean zero. 


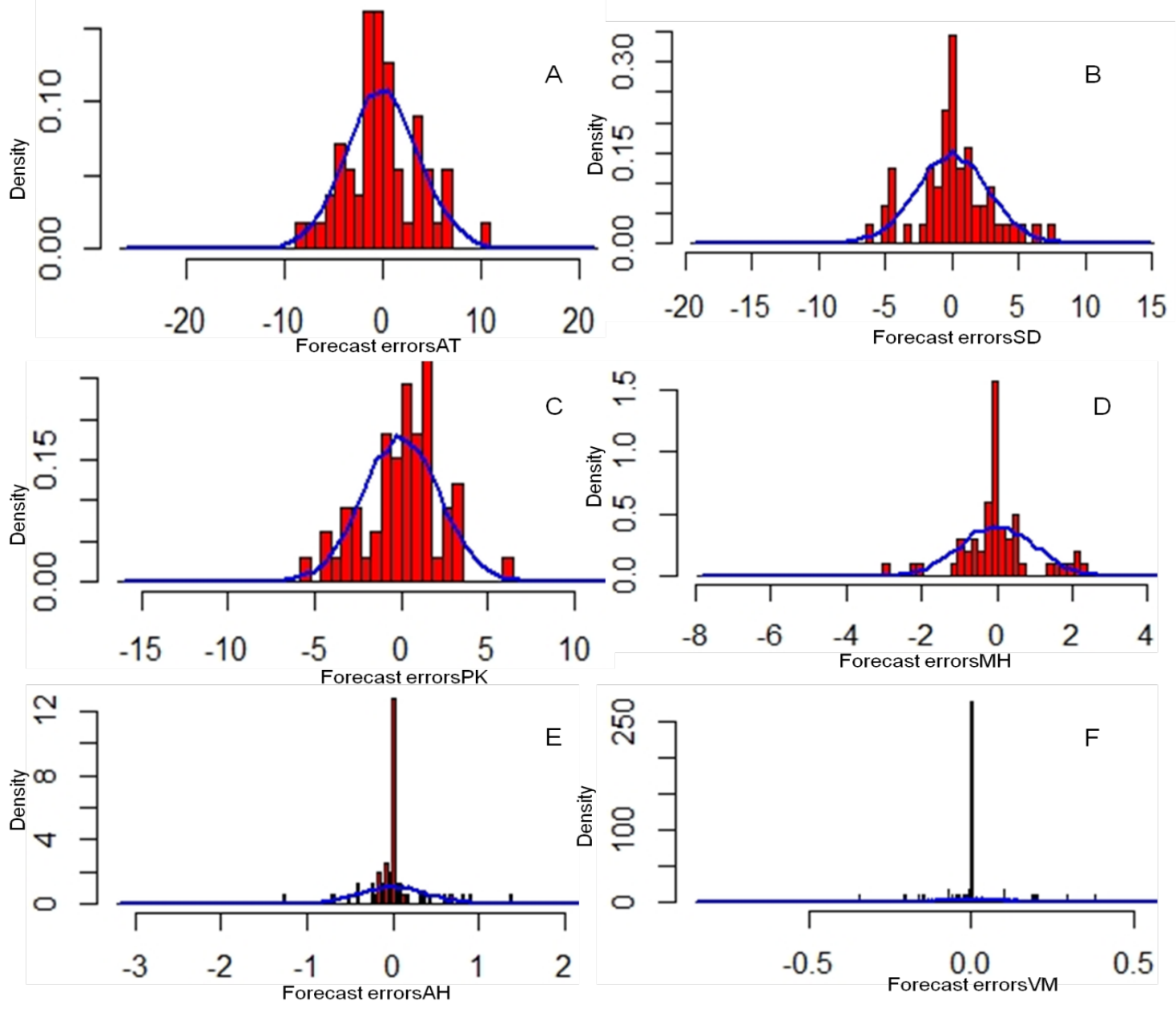

Figure 5. A distribution of forecast errors of six predictive model in An Thuan (A), Son Doc (B), Phu Khanh (C), My Hoa (D), An Hiep (E), Vam Mon (F) in Ham Luong river

There were no autocorrelations in the forecast errors, and the forecast errors were normally distributed with mean zero and constant variance in An Thuan, Son Doc, and Phu Khanh model. This suggests that the SES method provides an adequate predictive model for the forecast of salinity intrusion in An Thuan, Son Doc, and Phu Khanh, which probably cannot be improved upon. Furthermore, although the forecast errors in My Hoa, An Hiep, and Vam Mon was normally distributed with non-autocorrelations, this variance was not constant over time. It was likely that the SES in My Hoa, An Hiep, and Vam Mon could be improved upon by another forecasting technique.

\section{Conclusion}

As salinity intrusion continues to affect the quality of life, there is a need to have a framework that would find technical ways to monitor and forecast salinity intrusion in rivers. This study presents an application of the SES method to forecast salinity intrusion in HLR, based on salinity monitoring data from January 2017 to March 2019 obtained from the Center for Hydro-meteorological forecasting of Ben Tre province. The results showed that the SES method provides an adequate predictive model for forecast of salinity intrusion in An Thuan, Son Doc, and Phu Khanh. However, the SES in My Hoa, An Hiep, and Vam
Mon could be improved upon by another forecasting technique. Although the SES method cannot handle trends well, it is easy to implement and can be applied to other area as well. The results can be used by water resource operation, management in estuaries, and salinity change monitoring as well.

\section{Acknowledgment}

This research was funded by the project "Assessment of the environmental and socio-economic impact after dam construction in the Mekong estuarine system: the case of the Ba Lai estuary" under grant number ZEIN2015PR414. Furthermore, the authors would like to convey our thanks to Dr. Quan T. Lai (Institute of Tropical Biology, Vietnam Academy of Science and Technology), who provided us valuable advice on modeling of the Ham Luong river.

\section{References}

[1] Hamrick, J. M., 1992. A three-dimensional environmental fluid dynamics computer code: Theoretical and computational aspects, Spec. Rep. 317, 63 pp., Virginia Inst. of Mar. Sci., Gloucester Point, Va. 
[2] Hang, T. T. L., Tri, V. P. Đ., CTU, N. T. T., 2015. Salinity intrusion dynamics in a downstream river network of the Mekong river in the Vietnamese Mekong Delta under impacts of the Ba Lai culverts. Can Tho University Journal of Science, 139-149 (in Vietnamese)

[3] Huang, W., Foo, S., 2002. Neural network modeling of salinity variation in Apalachicola River. Water Research, 36(1), 356-362.

[4] Hyndman, R. J., Athanasopoulos, G., 2018. Forecasting: principles and practice (2nd edition). OTexts.

[5] Mahajan, S., Chen, L. J., Tsai, T. C., 2018. Short-Term PM2.5 Forecasting Using Exponential Smoothing Method: A Comparative Analysis. Sensors, 18(10), 3223.

[6] Montgomery, D. C., Johnson, L. A., Gardiner, J. S., 1990. Forecasting and Time Series Analysis, McGraw-Hill, Inc.

[7] Nguyen, A. D., Savenije, H. H., Pham, D. N., Tang, D. T., 2008. Using salt intrusion measurements to determine the freshwater discharge distribution over the branches of a multi-channel estuary: The Mekong Delta case. Estuarine, Coastal and Shelf Science, 77(3), 433-445.

[8] Ostertagova, E., Ostertag, O., 2012. Forecasting using simple exponential smoothing method. Acta Electrotechnica et Informatica, 12(3), 62-66.

[9] Phuong, T. B. N., Werapong, K., Donald, M., Tri, P. D.

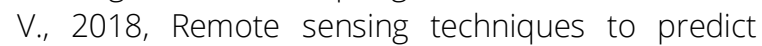
salinity intrusion: application for a data-poor area of the coastal Mekong Delta, Vietnam, International
Journal of Remote Sensing, 39(20), 6676-6691.

[10] Qiu, C., Wan, Y., 2013. Time series modeling and prediction of salinity in the Caloosahatchee River Estuary. Water Resources Research,49(9), 58045816.

[11] R, Core Team., 2016. R: A Language and Environment for Statistical Computing, R Foundation for Statistical Computing. (Version 3.3.1, Vienna, Austria). https://www.Rproject.org.

[12] Sheng, Y. P., 1990. Evolution of a three-dimensional curvilinear-grid hydrodynamic model for estuaries, lakes and coastal waters: CH3D, in Estuarine and Coastal Modeling, edited by M. L. Spaulding, pp. 40-49, Am. Soc. Civ. Eng., Reston, Va.

[13] Thach, P., Doan, T., 2001. Ben Tre Geography. Social Sciences Publishing House (in Vietnamese).

[14] Tran, T. X. M., Nguyen, D. V., 2006. Salinity Intrusion Trend in River and Canal Systems and Some Prevention Methods in Ben Tre Province. In: Proceedings of the Vietnam - Japan Estuary Workshop. August $22^{\text {nd }}-24^{\text {th }}$, Hanoi, Vietnam.

[15] Yorucu, V., 2003. The analysis of forecasting performance by using time series data for two Mediterranean islands. Review of Social, Economic \& Business Studies, 2, 175-196.

[16] Zhi-Peng, L. I., Hong, Y. U., Yun-Cai, L. I. U., Fu-Qiang, L. I. U., 2008. An improved adaptive exponential smoothing model for short-term travel time forecasting of urban arterial street. Acta automatica sinica, 34(11), 1404-1409. 